\title{
Recomendaciones para el estudio microbiológico de tejidos preservados para implantes
}

\author{
PATRICIA GARCÍA C., BÉATRICE HERVÉ E., CHRYSTAL JULIET L., EDUARDO TURNER G., CLAUDIO ARRETZ \\ V., JULIO ARRIAGADA V., CLAUDIO RAFOLS DEL C., ALBERTO PÉREZ C., JORGE VILLEGAS C., GLORIA M. \\ GONZÁLEZ G., PAULINA AGUIRRE H., JOSÉ MINGUELL U., MAURICIO OCQUETEAU P., ISABEL PIZARRO A., \\ FRANCISCO ANDRIGUETTI C. y ALONSO RODRÍGUEZ B.
}

\section{Recommendations for the microbiological study of tissues preserved for implants}

The implant of tissues in Medicine has enhanced the prognosis and/or quality of life of several diseases, however its utilization is not free of risks for the receptor. Because of this, a carefully selection of live or cadaveric donors and the microbiological control of tissues before its utilization are very important procedures in securing the quality of the procedure. Contamination of tissues may be intrinsic (because of unnoticed infection in the donor) or extrinsic (after the tissues has been harvested). These recommendations focus into the microbiological control of extrinsic contaminations, through its handling during the tissues harvest or during its processing for preservation. Most frequently used implants in our country (cardiac valves, osseus tissue, skin, hematopoyetic precursor cells and cornea) are analyzed and methodology is described according to existing data in the literature and through a review of procedures employed in foreing centers. As no one of implants is completely sterile it is very important to analyze too the recommendations for handling contaminated cultures. As authors we expect that this document will be useful and in brief, we can exhibit national multicenter figures constructed with comparable methodologies.

Key words: Tissue implants; Contamination; Microbiological control.

Palabras claves: Implante de tejidos; Contaminación; Control microbiológico.

\section{Introducción}

Cada vez con mayor frecuencia existen patologías que requieren como parte de su terapia el uso de tejidos homólogos para implantes, los que han mejorado el pronóstico de estas enfermedades.

Se ha descrito un aumento significativo del número de implantes de tejidos como válvulas cardíacas, tejido óseo y músculo-esquelético, piel, células progenitores de médula ósea, córnea, células pancreáticas y duramadre. En E.U.A., los implantes músculo-esqueléticos han aumentado desde 350.000 en 1990 a más de 800.000 en el 2002 y se cuenta con un organismo perteneciente a FDA, el Center for Biologics Evaluation and Research (CBER), que regula los productos bio-

\footnotetext{
Participaron en la elaboración de este documento las siguientes instituciones (entre paréntesis los expertos consultados en orden de aparición en el texto):

Sociedad Chilena de Infectología (PGC, BHE, CJL): Microbiólogas delegadas por el Comité de Microbiología Clínica.

Hospital DIPRECA (ETG) y Hospital Clínico de la Pontificia Universidad Católica de Chile (CAV): Injerto valvular. Hospital DIPRECA (JAV, CR Del C) y Hospital del Trabajador (APC): Injerto óseo.

Hospital Luis Calvo Mackenna (JVC, GGG) y Comisión Chilena de Energía Nuclear (PAH): Injerto de piel.

Clínica Las Condes (JMU) y Hospital Clínico de la Pontificia Universidad Católica de Chile (MOP, IPA): Injerto de precursores hematopoyéticos.

Hospital Del Salvador (FAC, ARB): Injerto de córnea.
} 
lógicos para prevenir la transmisión de enfermedades, y asegura la calidad y eficacia del producto ${ }^{1}$.

Por la necesidad de disponer de tejidos para implantes, en las últimas décadas ha surgido la necesidad de crear bancos que permitan almacenar tejidos de manera segura para los futuros receptores. En nuestro país se cuenta con numerosos centros que manejan este tipo de bancos, que se rigen por protocolos basados en experiencias foráneas que no especifican detalladamente los procedimientos para el estudio microbiológicos. Esto ha llevado a que cada centro adapte los protocolos a su realidad local.

Dado que no existe una metodología común para asegurar la calidad microbiológica de los tejidos almacenados, hemos intentado a través de las siguientes recomendaciones unificar estos procedimientos (Figura 1).

Se trataran específicamente los siguientes tejidos para implantes preservados en bancos: válvulas cardíacas, tejido óseo, piel, células progenitoras hematopoyéticas y córnea.

$\mathrm{Se}$ excluyen de estas recomendaciones los criterios de selección del donante destinados a evitar tanto la transmisión de enfermedades infecciosas latentes desde un donante vivo o cadáver al receptor (infección por VIH, HTLV-1, hepatitis B y C, citomegalovirus, virus de Epstein Barr, toxoplasmosis) como la transmisión de infecciones intrínsecas bacterianas o fúngicas que estén desarrollándose en el donante.
Sí se abordaran aquellos aspectos relacionados con la monitorización microbiológica de la contaminación extrínseca de los tejidos, que está justificada porque:

- A pesar que la incidencia de infecciones clínicamente significativas post-implante no son de gran magnitud en estudios prospectivos, la contaminación de los tejidos preservados se asocia a complicaciones infecciosas que pueden ser devastadoras. Por lo tanto, la buena calidad microbiológica de estos tejidos disminuye el riesgo de infección en el receptor.

La contaminación puede ocurrir en cada una de las etapas del proceso: procuración o cosecha, procesamiento para la preservación, preservación propiamente tal o durante el implante en el receptor (Figura 1).

- Los tejidos para implantes por ser productos biológicos, no resisten procedimientos convencionales de esterilización (oxido de etileno, radiaciones gamma), pues pierden su funcionalidad o son tóxicos, por lo que la ausencia de contaminación depende del control en cada una de las etapas.

- Existen pocos datos en Chile sobre la magnitud de la contaminación de los tejidos preservados para implantes y las conductas a llevar a cabo una vez que ésta se detecta.

El inconveniente de los estudios microbiológicos destinados a asegurar la calidad de los implantes es que la contaminación de los tejidos

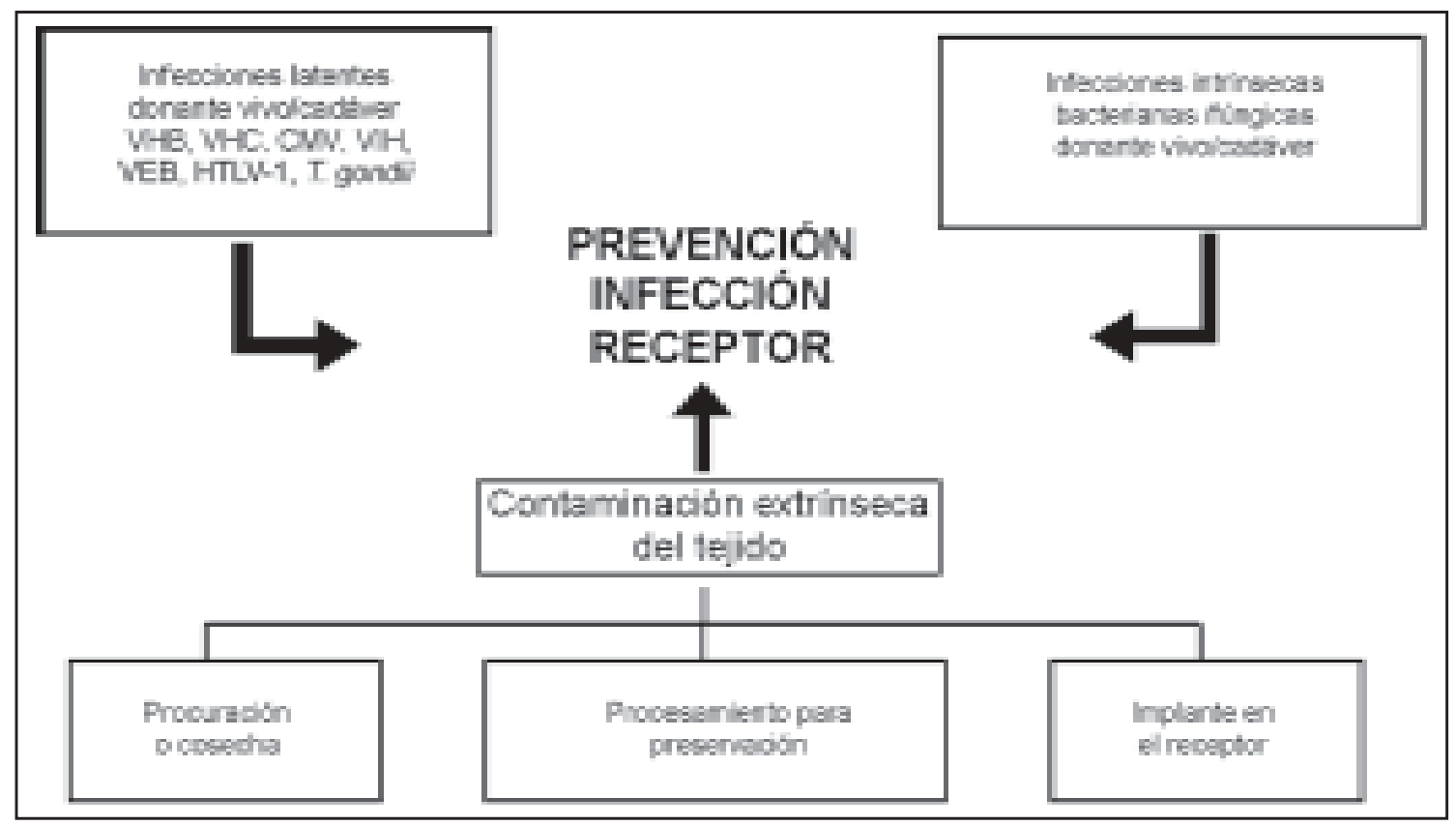

Figura 1. Etapas en el aseguramiento de la calidad de los tejidos para implantes. 
utilizados puede provenir del donante (infección asintomática o colonización), de la manipulación durante la procuración, de las soluciones preservantes o del laboratorio que procesa las muestras para el estudio microbiológico. Este último riesgo puede ser minimizado cuando las muestras son sembradas directamente durante la procuración evitando así ser manipuladas en el laboratorio de microbiología con posterioridad.

\section{Estudio microbiológico de las válvulas cardíacas}

\section{Introducción}

El uso de homoinjertos en cirugía cardíaca se inició en 1962 en forma separada por Barratt Boyes en Nueva Zelanda y Ross en Inglaterra con los primeros reemplazos de válvulas aórticas. Ross también introdujo el autoinjerto pulmonar para reemplazo valvular aórtico en 1967 (en esta operación se usa la válvula pulmonar del paciente para reemplazar la válvula aórtica enferma y se implanta un homoinjerto pulmonar para reestablecer la continuidad entre el tracto de salida del ventrículo derecho y la arteria pulmonar) y el uso de homoinjertos para reconstrucción del tracto de salida del ventrículo derecho en pacientes con cardiopatías congénitas. Estas opciones de reemplazo valvular se mantuvieron limitadas a un número restringido de cirujanos por muchos $a_{n}{ }^{2}$. Las razones principales tuvieron que ver con la dificultad para conseguirlas y asegurar su esterilidad, mayor dificultad para implantarlas y la aparición de las prótesis comerciales, inicialmente mecánicas y luego porcinas con ventajas evidentes de disponibilidad y mayor facilidad de implantación. Sin embargo, los problemas de estas prótesis -necesidad de anticoagulación y riesgo de tromboembolismo en las válvulas mecánicas, durabilidad limitada y obstrucción en las porcinas- reactivaron el interés por el uso de los homoinjertos.

La introducción de la criopreservación por O'Brien de Australia en 1975 permitió solucionar parcialmente el problema de disponibilidad al permitir el almacenaje indefinido ${ }^{3,4}$. Hasta ese momento, las válvulas se preservaban a $4^{\circ} \mathrm{C}$ y se consideraba prudente usarlas dentro de un máximo de 10 semanas desde su procuración. La criopreservación se realiza en un gabinete de flujo laminar una vez completado el ciclo de esterilización en antimicrobianos, extrayendo las válvulas a un medio de cultivo sin antimicrobianos para esperar "en cuarentena" la confirmación de la ausencia de contaminación. Luego se traspa- san a bolsas especiales agregando dimetil sulfóxido (DMSO), sellándolas y cubriéndolas con una segunda bolsa. El proceso de criopreservación requiere de un congelador programado computacionalmente y con termistor de registro continuo de manera de bajar la temperatura $1^{\circ} \mathrm{C}$ por minuto. Posteriormente se trasfiere a un depósito con nitrógeno en fase líquida (aproximadamente $\left.-150^{\circ} \mathrm{C}\right)$.

Los homoinjertos de válvulas cardíacas son usados actualmente en la mayoría de los casos como conductos valvulados en operaciones sobre el corazón derecho. Sin embargo, en los últimos años se han empleado en forma creciente en la reparación de hipoplasia del corazón izquierdo, reemplazo de aorta ascendente en lesiones valvulares aórticas, especialmente asociadas a endocarditis bacteriana.

Las ventajas principales de los homoinjertos para reemplazo valvular aórtico tienen que ver con mejor hemodinamia (ausencia de gradiente transvalvular), ausencia de tromboembolismo, mayor durabilidad en comparación a las prótesis comerciales biológicas, resistencia a las infecciones y menor costo intrínseco. Las desventajas más importantes son su escasez, dificultad mayor de implantación y durabilidad limitada en pacientes jóvenes ${ }^{5,6}$.

En Chile el uso sistemático de homoinjertos se inició en 1994 con válvulas almacenadas a $4^{\circ} \mathrm{C}$ en un banco creado en el Hospital DIPRECA. Éste permaneció activo hasta alrededor de 1999 en que fue reemplazado por bancos de válvulas criopreservadas en el Hospital Clínico de la Pontificia Universidad Católica y en la Clínica Las Condes.

Las válvulas cardíacas son obtenidas desde donante de órganos múltiples o desde necropsias. En el primer caso las tasas de contaminación son cercanas a $12 \%$ y en el segundo, alrededor de 50 a $60 \%$. La incubación de las válvulas en una solución de antibacterianos más medio de cultivo de tejido (M199) a $37^{\circ} \mathrm{C}$ por 24 horas, logra esterilizar cerca de $100 \%$ de las válvulas cuando son adecuadamente manipuladas en gabinetes de flujo laminar. Sin embargo, la manipulación de las válvulas en medios no estériles (por ej. en el pabellón quirúrgico) genera una contaminación de alrededor de 3 a $5 \%$ por microorganismos de la flora de la piel especialmente Staphylococcus coagulasa negativa ${ }^{2,7-10}$.

\section{Procedimiento microbiológico}

Para evaluar la calidad microbiológica de las válvulas cardíacas obtenidas de donante cadáver (Figura 2), antes de ser implantadas a un re- 


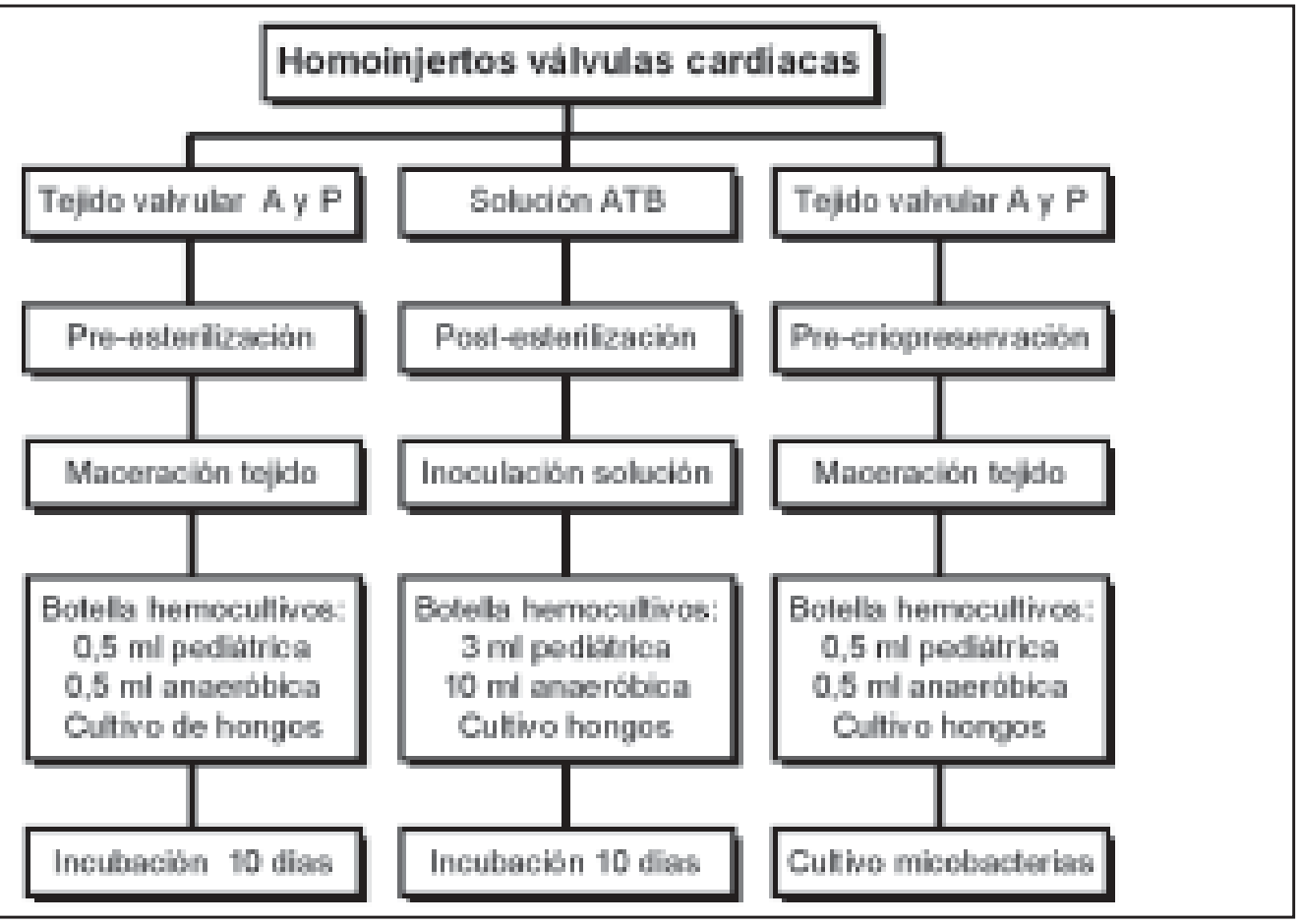

Figura 2. Estudio de la calidad microbiológica de la válvulas cardíacas para implante. *A: aórtico; P: pulmonar; ATB: antibiótica.

ceptor, se recomienda estudiar ambas válvulas -aórtica y pulmonar- en las tres etapas de su procesamiento: tejido valvular antes de la esterilización, solución de contiene las válvulas post esterilización y solución que contiene las válvulas pre criopreservación ${ }^{3}$ :

Tejido valvular antes de la esterilización: Envíe un trozo de tejido en frasco estéril (especificando si se trata de borde de la aorta, arteria pulmonar o trozo del corazón extraído) con $\mathrm{NaCl}$ 9\%o estéril para evitar la desecación. Macere con dos hojas de bisturí en placa de Petri bajo gabinete de flujo laminar e inocule el homogenizado en dos botellas de hemocultivos (mínimo $0,5 \mathrm{ml} \mathrm{a}$ cada botella) e incube a $37^{\circ} \mathrm{C}$ durante 10 días. A los 10 días de incubación, subcultive en una placa de agar sangre, agar chocolate y agar Sabouraud.

Solución de cultivo post esterilización: De la solución M119 sin antimicrobianos a la que se traspasaron las válvulas en espera de confirmar esterilidad, tome aproximadamente $15 \mathrm{ml}$ e inocule en dos botellas de hemocultivos (aeróbico y anaeróbico). Incube durante 10 días a $37^{\circ} \mathrm{C}$ y luego subcultive en placa de agar sangre, agar chocolate y agar Sabouraud.

Líquido preservante antes de la criopreservación: Proceda como en el párrafo anterior, agregando un cultivo de micobacterias.

\section{Conducta frente a cultivos positivos:}

Los cultivos positivos de las válvulas ya son frecuentemente positivos antes de iniciar su proceso de antisepsia por antimicrobianos. Sin embargo, cultivos positivos no son aceptables en las etapas posteriores que conducen a la criopreservación. La manipulación de los homoinjertos descongelados en pabellón quirúrgico puede generar contaminación por microorganismos en 3 a $5 \%$ de los cultivos obtenidos en este ambiente y no requieren conductas específicas, sólo control clínico del enfermo y ecográfico de la válvula implantada, situación habitual a cualquier recambio valvular.

Los cultivos positivos con crecimiento de hongos en cualquier etapa del proceso obligan a descartar la(s) válvula(s) pues es muy difícil erradicar con certeza contaminaciones fúngicas en estos tejidos con la metodología empleada.

\section{Estudio microbiológico del tejido óseo}

\section{Introducción}

El tejido óseo, así como cartílagos y ligamentos, han sido utilizado durante muchos años con bastante éxito, ya sea como material de reparación o reemplazo en procedimientos quirúrgicos de traumatología. 
Las propiedades biomecánicas de este tejido permiten su uso para reparar defectos puntuales o como grandes piezas que se utilizan para reemplazo de zonas de hueso que deben ser extraídas debido a procesos tumorales.

En un banco de huesos se almacenan, debidamente procesados y congelados, huesos de dos orígenes ${ }^{11,12}$ :

- donante cadáver, del cual se extraen por procuración, grandes trozos óseos, y osteocondrales con o sin ligamentos, que van a ser utilizados en terapia de reemplazo, y

- donante vivo, del cual, al ser intervenido para instalar una prótesis de cadera, se extrae la cabeza femoral, la que es reservada para posteriormente ser utilizada en reparaciones.

Dado que estos procedimientos involucran el implante de un tejido orgánico desvitalizado que actúa como cuerpo extraño, con poca capacidad de respuesta inmune, cualquier infección, si bien son infrecuentes, puede ser clínicamente muy significativa $^{13,14}$.

Es así que en el procesamiento de las piezas óseas para su almacenamiento en un banco de huesos, ya sea de donante vivo o cadáver, debe contar con un adecuado control microbiológico que permita utilizarlo con relativa seguridad para el paciente receptor. Actualmente no es posible considerar las piezas óseas como material estéril a pesar de presentar cultivos negativos, ya que para preservar las propiedades biomecánicas del tejido, así como para evitar la toxicidad residual, en la mayoría de los casos no puede ser sometido a los procesos esporicidas que hoy se conocen (oxido de etileno, rayos gamma) ${ }^{15}$.

A la luz de la literatura y reportes existentes en la actualidad $^{12,16,17}$, el riesgo de obtener piezas contaminadas oscila entre 11 y $66 \%$, dependiendo de:

- Tipo de donante (cadáver mayor riesgo que donante vivo) y selección previa del donante (criterios de exclusión).

- Ambiente de procuración (el depósito de cadáveres tiene mayor riesgo que el pabellón quirúrgico).

- En el caso de donante cadáver: causa de muerte (el trauma abdominal tiene mayor riesgo), temperatura de almacenamiento del cadáver (menor riesgo a menos de $4^{\circ} \mathrm{C}$ ), tiempo transcurrido entre la muerte y la procuración (tiempo máximo aceptable: 24 horas).

- Número de personas en el equipo de procuración: el riesgo aumenta por cada persona extra que se incorpora al equipo.

Existen dos categorías de microorganismos que pueden contaminar las piezas óseas ${ }^{16}$ :
- Microorganismos de baja virulencia, que corresponden principalmente a especies grampositivas provenientes de la piel y que reflejan en su mayoría contaminación durante los procedimientos de procuración y procesamiento de las piezas.

- Microorganismos de alta virulencia, que incluye especies gramnegativas provenientes de la flora intestinal y en su mayoría representan la diseminación hematógena que ocurre en las últimas etapas antes de la muerte.

\section{Procedimiento microbiológico}

\section{Consideraciones:}

Tipo de muestra. Durante largo tiempo se recomendó para control de piezas óseas de banco, el cultivo de tórula en placas o caldo. Esta tórula debía pasarse prolijamente por zonas representativas de la superficie y médula ósea. Sin embargo, reportes recientes demuestran que la sensibilidad y el valor predictor negativo de esta muestra son muy bajos (10 y $13 \%$, respectivamente) cuando se comparan con el estándar de oro que consiste en cultivar la pieza ósea completa. Es así que actualmente se prefiere el cultivo de trozos de hueso entero que son inoculados en diferentes medios de cultivo líquidos e incubados por periodos que oscilan entre 7 y 14 días según los diferentes protocolos. El CDC de Atlanta recomendó en el año 2002 el uso de tórula y hueso completo, lo que a nuestro juicio es una redundancia, dada la baja sensibilidad del método de la tórula ${ }^{15,18}$.

Medios de cultivo. Tradicionalmente se ha utilizado caldo cerebro corazón (BHI), que permite la detección de levaduras y las principales bacterias aerobias. Dado reportes recientes de infecciones severas (e incluso un caso fatal) debido a anaerobios que no habían sido detectados en el hueso donante (Clostridium sordellii y Clostridium sp), es preciso incluir un medio que permita el desarrollo de este tipo de bacterias ${ }^{15,19}$.

Número de muestras. A mayor número de muestras cultivadas por pieza, aumenta la sensibilidad, pero también aumenta la proporción de falsos positivos en que se estaría detectando cargas bacterianas muy bajas, con escasa repercusión clínica. Cuando se cultivan cuatro muestras por pieza, se llega a $90 \%$ de falsos positi$\operatorname{vos}^{18}$.

Momento de obtención de la muestra. Algunos protocolos incluyen etapas de "lavado" mediante enjuagues a presión o descontaminación por sumersión de la pieza ósea en soluciones de antimicrobianos. En el primer caso, debe ser 
requisito del protocolo la utilización de agua estéril para los lavados, no siendo de utilidad cultivar el agua post-enjuague. En ambos casos, si las muestras de hueso son obtenidas después del procedimiento, se debe tener en cuenta la posibilidad que la solución antibacteriana produzca una bacteriostasis que favorezca resultados falsamente negativos ${ }^{15,17,20}$.

Otras muestras. Una proporción importante de publicaciones recomienda en el caso de donante cadáver, obtener un hemocultivo al momento de la procuración, el cual al ser positivo obligaría a descartar todas las piezas de ese paciente, o someterlas a irradiación ${ }^{21}$.

\section{Recomendaciones (Figura 3):}

Tomando en cuenta las consideraciones antes mencionadas, y con el fin de promover un esquema de trabajo racional y costo-efectivo, se recomienda:

- Realizar cultivo de trozo de hueso a toda pieza obtenida para banco de hueso.

- Inocular dos caldos por cada pieza: un tubo de BHI y un tubo de tioglicolato anaerobios. En caso de tener que elegir uno, prefiera el uso de tioglicolato anaerobios.

- Realizar la inoculación de los caldos en pabellón, al momento de procurar la pieza o con posterioridad a su procesamiento, según las especificaciones del protocolo.

- Incubar ambos caldos a $35^{\circ} \mathrm{C}$ por 7 días y subcultivar frente a cualquier turbidez o al séptimo día. Subcultivo de BHI en placa de agar sangre, chocolate y Sabouraud. Subcul- tivo de tioglicolato en placa de agar sangre anaerobios. Identificación de cepas aisladas según metodología estándar.

- Realizar antibiograma a toda cepa aislada, puesto que puede servir de antecedente frente a una situación de infección clínica o frente a brotes.

- Guardar las piezas a $-80^{\circ} \mathrm{C}$ hasta que sean informadas como negativas.

- En caso de detectar piezas con microbiología positiva, elimínelas.

- En caso de grandes piezas, (donante cadáver), sería conveniente realizar irradiación con dosis bajas (<3Mrad), especialmente si se ha obtenido cultivo positivo en alguna de las piezas de ese donante.

- Obtener hemocultivo siempre que sea posible en donante cadáver, al momento de la procuración

\section{Conducta frente a una pieza contaminada:}

- Cabeza femoral: elimínela

- Grandes piezas: elimínelas o irrádielas. La irradiación con grandes dosis de rayos gamma (> 3Mrad), es efectiva pero debilita la estructura del colágeno. Al utilizar dosis menores que $3 \mathrm{Mrad}$, se puede eliminar patógenos sin dañar esta estructura. Sin embargo, dosis menores de 3Mrad no eliminan virus, lo que es un factor a tener en cuenta al momento de evaluar los riesgos ${ }^{22}$. Hay autores que recomiendan asociar irradiación en dosis bajas con inmersión previa en soluciones antimicrobianas. Aún así, el uso de piezas óseas para implante,

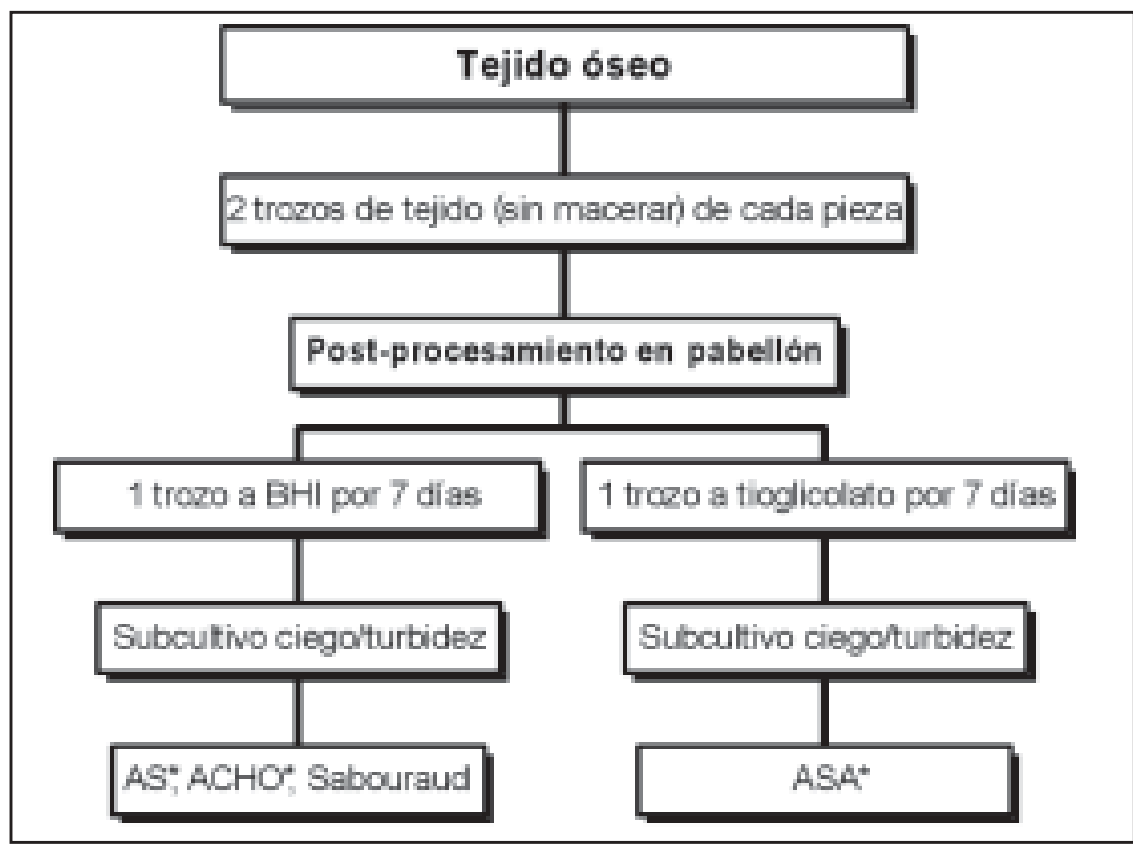

Figura 3. Estudio de la calidad microbiológica del tejido óseo para implante. AS: agar sangre; ACHO: agar chocolate; ASA: agar sangre anaerobios; BHI: caldo cerebro-corazón. 
tiene un riesgo de infección: si bien el riesgo utilizando cabezas femorales es cercano a $0 \%$, para las grandes piezas es entre 4 y $5 \%$, siendo aproximadamente la mitad de los casos atribuible a la pieza implantada, a pesar de haber tenido controles microbiológicos negativos ${ }^{11,12,14,17,18}$.

En conclusión, según las características del control microbiológico que es posible realizar, los médicos clínicos que utilizan piezas óseas de banco de huesos deben estar conscientes que trabajan con tejidos que no son $100 \%$ estériles, aunque sí bastante seguros, dado que cultivos negativos implican que, de existir contaminación, la carga bacteriana es baja y en la mayor parte de los casos, no significa riesgo clínico ${ }^{16,18,19,22}$.

\section{Estudio microbiológico de piel de banco}

\section{Introducción}

Desde los inicios de la cirugía reparadora se han utilizado los injertos de piel homóloga en la cobertura de quemaduras de espesor total, y a mediados de la década del setenta, su aplicación adquirió verdadera relevancia, cuando se impuso el concepto de escarectomía precoz y cobertura inmediata ${ }^{23}$.

En nuestro país se realiza la técnica de escarectomía precoz de manera sistemática desde comienzos de los ochenta; sin embargo, las limitaciones en nuestro medio hicieron optar primero por el heteroinjerto fresco de piel porcina para dar cobertura inmediata, reservando el injerto homólogo para casos y condiciones muy particulares.

En el resto del mundo, se plantearon dos proyectos alternativos: la aplicación de Injertos homólogos de donante cadáver ${ }^{24,25}$ y el desarrollo industrial de sustitutos de piel artificiales (aloinjertos). El primero se puso en práctica, inicialmente en China y posteriormente en los Servicios de Salud Europeos ${ }^{26,27}$; el segundo se desarrolló principalmente a partir de la experiencia de Burke en Boston. De alguna manera, como se advierte en nuestra experiencia, el carácter y la estructura de los servicios de salud condiciona, facilita o impulsa a avanzar en una u otra dirección.

Durante las décadas del ochenta y noventa, el uso de injertos homólogos fue esporádico, ligada al rescate de víctimas de quemaduras extensas, y debiendo utilizarse donantes vivos: familiares o amigos del paciente ${ }^{28}$. La experiencia con donantes solidarios, aparte de sus excelentes resultados clínicos y gran valor testimonial, puso de manifiesto inmediatamente sus limitaciones. La mane- ra de superar estas limitaciones fue desarrollar un banco de piel humana de donante cadavérico ${ }^{29,30}$.

En Chile, el proyecto para establecer un Laboratorio de Procesamiento de Tejidos Biológicos Radioesterilizados fue presentado en la Comisión Chilena de Energía Nuclear, CCHEN, en 1996, y como Proyecto de Cooperación Técnica al Organismo Internacional de Energía Atómica (OIEA). En 1998, Chile, junto con otros países de Latinoamérica, entró a formar parte del proyecto INT/6/049; luego de un periodo de capacitación e implementación del laboratorio se comenzó con el trabajo de procesamiento de los tejidos.

A partir del año 2001 se comenzó el procesamiento de piel de donante cadavérico en forma continua, con el primer grupo de ablación en el Hospital Luis Calvo Mackenna. Para el procesamiento de estos tejidos se ha desarrollado procedimientos rigurosos basados en normas establecidas por las Asociaciones de Bancos de Tejidos de Europa, Asia y Norteamérica ${ }^{31}$; dentro de este sistema de calidad, entre otras cosas se ha generando y se están utilizando formatos que permiten recopilar información y tener un completo trazado de cada tejido procesado.

Para lograr la obtención de un tejido seguro en la aplicación clínica se deben seguir las especificaciones técnicas en cada una de las etapas: selección del donante, ablación, procesamiento, almacenamiento y distribución.

Los criterios de selección del donante de tejidos son los mismos que para los donantes multiorgánicos con valoración de la historia médico-social, exploración física y determinaciones serológicas para VHB, VHC VIH y sífilis, además de la determinación de grupo y Rh, y condiciones especificas como el daño estructural de la piel en las zonas de ablación (tumores-heridasescoriaciones-quemaduras, etc), infección sistémica no controlada o local y dificultades en la extracción.

\section{Técnica de ablación}

Efectuada con técnica aséptica, en quirófano, se realiza un rasurado prolijo de las zonas de extracción con bisturí simple o rasuradora eléctrica, aseo con solución jabonosa de clorhexidina y antisepsia con solución de tintura de clorhexidina, colocación de campos estériles, posteriormente se extrae la piel con dermátomo eléctrico (el espesor de la toma es de 0,25 a 0,30 mm). En conjunto se toma, entre extremidades inferiores y dorso, un promedio de 4.000 a $5.000 \mathrm{~cm}^{2}$.

El tejido se coloca en la solución de transporte (Ringer lactato $500 \mathrm{cc}$ con penicilina sódica $1.000 .000 \mathrm{UI}$ y gentamicina $80 \mathrm{mg}$ ) en frascos 
de vidrio con tapa rosca, estériles, previamente rotulados, cubiertos con una doble bolsa estéril.

A continuación se procede a vendar prolijamente las zonas para entregar el cadáver a los familiares.

Luego el material es trasladado al laboratorio de procesado colocando los frascos en la heladera a $4^{\circ} \mathrm{C}$ hasta su procesamiento, el cual debe realizarse antes de 56 horas de extraído el tejido.

\section{Procesamiento y control microbiológico}

Todas las etapas de procesamiento se realizan en forma aséptica. Para ello se dispone de una campana de flujo laminar clase 100 , donde se realiza el lavado del tejido con $\mathrm{NaCl} 9 \%$ estéril (4 lavados), se toman inmediatamente antes de empacar 10 muestras de $1 \mathrm{~cm}^{2}$ para estudio microbiológico pre-esterilización. Se regularizan los bordes y se cortan láminas de 6 por $12 \mathrm{~cm}$ (Figura 4).
El tejido preparado se coloca en solución de criopreservación (Ringer lactato con $10 \%$ de glicerol) a $4^{\circ} \mathrm{C}$ durante una hora, se retira de la heladera y bajo flujo laminar se coloca cada muestra entre dos láminas de tul y se embalan en doble bolsa de polietileno de 60 micras (selladas con calor) con los rótulos correspondientes $\left(\mathrm{N}^{\circ}\right.$ de Ficha Clínica de Comisión Chilena de Energía Nuclear).

El material procesado se coloca en un congelador secuencial con gradiente de $-1^{\circ} \mathrm{C}$ por minuto hasta alcanzar los $-80^{\circ} \mathrm{C}$. El tejido se esteriliza con radiación gamma en fuente de Cesio 137 a $25 \mathrm{kGy}$ por 14 horas en hielo seco $\left(\mathrm{t}^{\circ}-90^{\circ} \mathrm{C}\right)$.

Las diez muestras de tejido tomadas pre-esterilización se cultivan durante 5 días en forma cuantitativa ("bioburden"). Si el recuento bacteriano es $<1.000 \mathrm{ufc} / \mathrm{cm}^{2}$ se lleva a radiación subesterilizante con una dosis de 1 a 3 kGy, y luego se recultivan por 10 días; si el resultado

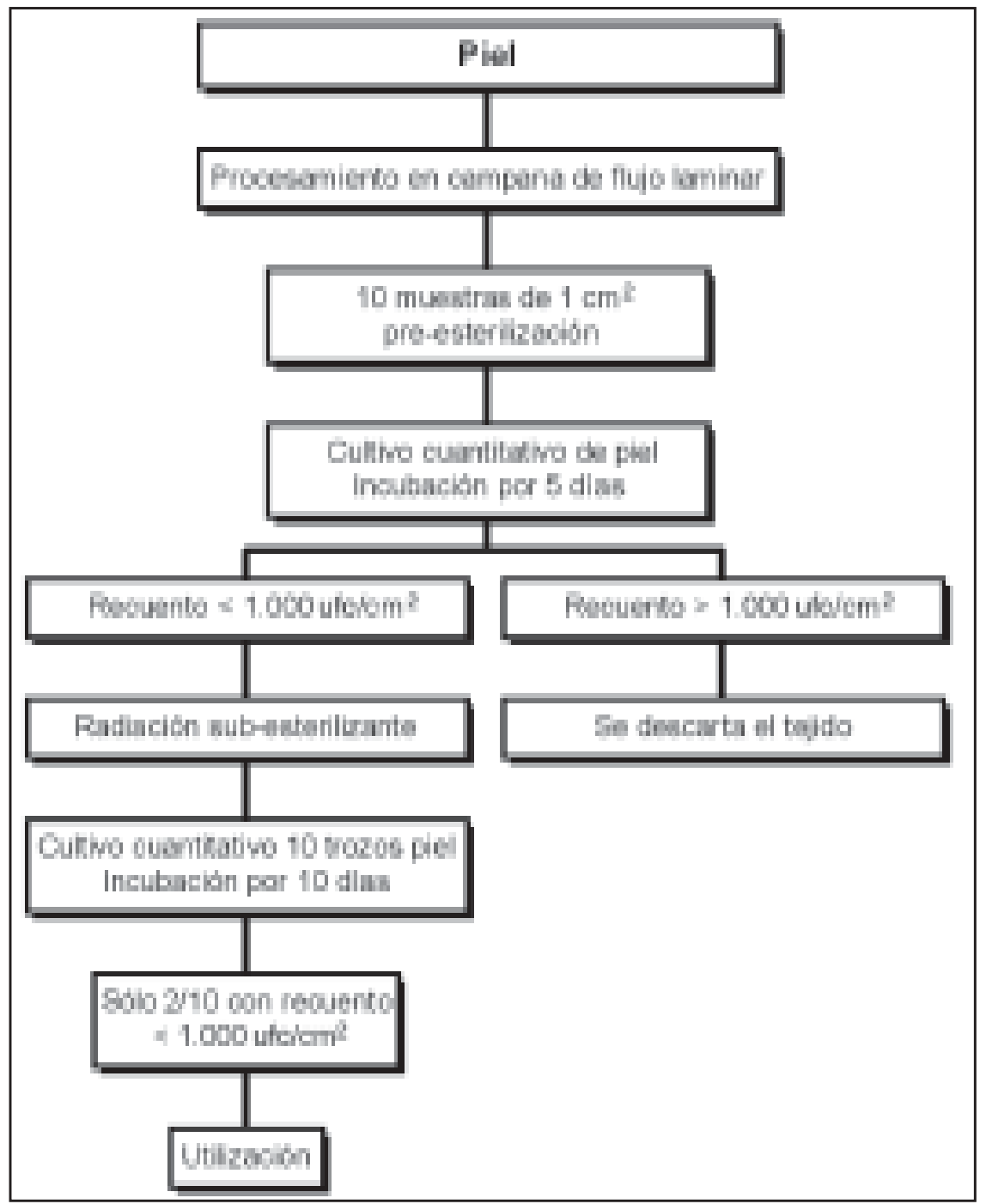

Figura 4. Control microbiológico de la piel para implantes. 
es de menos de dos muestras positivas, el tejido se libera para su utilización.

El tejido obtenido se rechaza si: el recuento bacteriano del tejido preesterilización es mayor a $1.000 \mathrm{ufc} / \mathrm{cm}^{2}$, si más de dos muestras son positivas post radiación subesterilizante, o cuando se rompe la cadena de frío.

\section{Almacenamiento y distribución}

Para el almacenamiento de estos tejidos se dispone de un congelador de $-80^{\circ} \mathrm{C}$, temperatura a la cual los tejidos estériles pueden permanecer hasta 5 años.

Una vez realizada la solicitud, se retiran los sobres del banco y se trasladan en hielo seco al establecimiento.

Bajo condiciones estériles, se procede a la apertura de las bolsas y colocación de las muestras en $\mathrm{NaCl}$ 9\%o estéril o ringer lactato a temperatura ambiente, colocando los injertos con la técnica quirúrgica habitual.

Posteriormente se eleva un informe al banco de piel sobre los resultados obtenidos con la colocación.

\section{Estudio microbiológico de células progenitoras obtenidas de sangre periférica, médula ósea o cordón umbilical}

\section{Introducción}

Históricamente, la médula ósea ha sido la fuente primaria de obtención de células progenitoras (troncales) hematopoyéticas para ser usadas en trasplante. Sin embargo, desde más de una década se está utilizando, como fuente alternativa de células progenitoras, la sangre periférica de donantes autólogos o alogeneicos, cuyas células troncales hematopoyéticas han sido movilizadas desde la médula ósea por factores estimuladores de crecimiento. De igual forma, se utiliza como fuente de células progenitoras, cosechas de sangre de cordón umbilical.

Es conocido que durante las diferentes etapas de los procesos de obtención, preparación y criopreservación de células progenitoras, cualquiera sea la fuente, existe riesgo de contaminación ${ }^{32}$.

Sin embargo, con la automatización de los procedimientos para cosechar (excepto médula ósea), manipular ex vivo y preparar el material para la criopreservación, los riesgos de contaminación han disminuido notablemente. En este sentido ha sido importante el desarrollo de procedimientos en circuito cerrado, los que además se realizan en un ambiente de aire filtrado estéril proporcionado por gabinetes de bioseguridad clase II.
En la mayoría de los casos, la contaminación se produce al momento de la obtención de la cosecha, particularmente en médula ósea y sangre de cordón, y no durante el procesamiento o descongelamiento previo a su infusión al paciente ${ }^{33}$.

\section{Procedimiento microbiológico (Figura 5) Cosecha de células progenitoras desde sangre periférica: obtención de muestras para cultivo microbiológico:}

\section{Pre-leucoaféresis}

- Operador de máquinas de leucoaféresis:

- lavado concurrente de manos

- utilización de guantes

- Preparación de la piel:

- Limpieza:

Limpie el área de la piel a puncionar con lavador quirúrgico (solución espumosa) formando círculos concéntricos de aproximadamente $5 \mathrm{~cm}$ de diámetro. Deje actuar por 30 segundos, sin que ella se seque, antes de pasar a la etapa siguiente. En caso que el paciente sea alérgico al yodo, realice la limpieza de la piel con alcohol al $70 \%$ y espere que se seque.

\section{- Desinfección:}

Aplique povidona yodada en el área a puncionar formando círculos concéntricos de aproximadamente $5 \mathrm{~cm}$ de diámetro. Espere 30 segundos para lograr el efecto bacteriostático de la povidona. Puncione sin volver a tocar el área de la piel que ya se ha decontaminado. Si es necesaria una nueva palpación de la vena, debe utilizar guantes estériles.

- Instalación de catéteres centrales:

En aquellos casos en que se requiere de la instalación de un catéter central, éste debe ser instalado en pabellón quirúrgico, con la debida anticipación y siguiendo las técnicas asépticas asociadas.

- Mantención de la línea venosa:

- Evite en todo momento la manipulación innecesaria de la vía.

- Cubra el sitio de punción con una gasa estéril de forma de proteger la entrada de la aguja en la piel.

- Ante cualquier manipulación de la vía venosa, manéjela con técnica aséptica.

- Una vez finalizada la cosecha cierre la bolsa y envíela al laboratorio de criopreservación (no tome en esta etapa una muestra para cultivo microbiológico). 


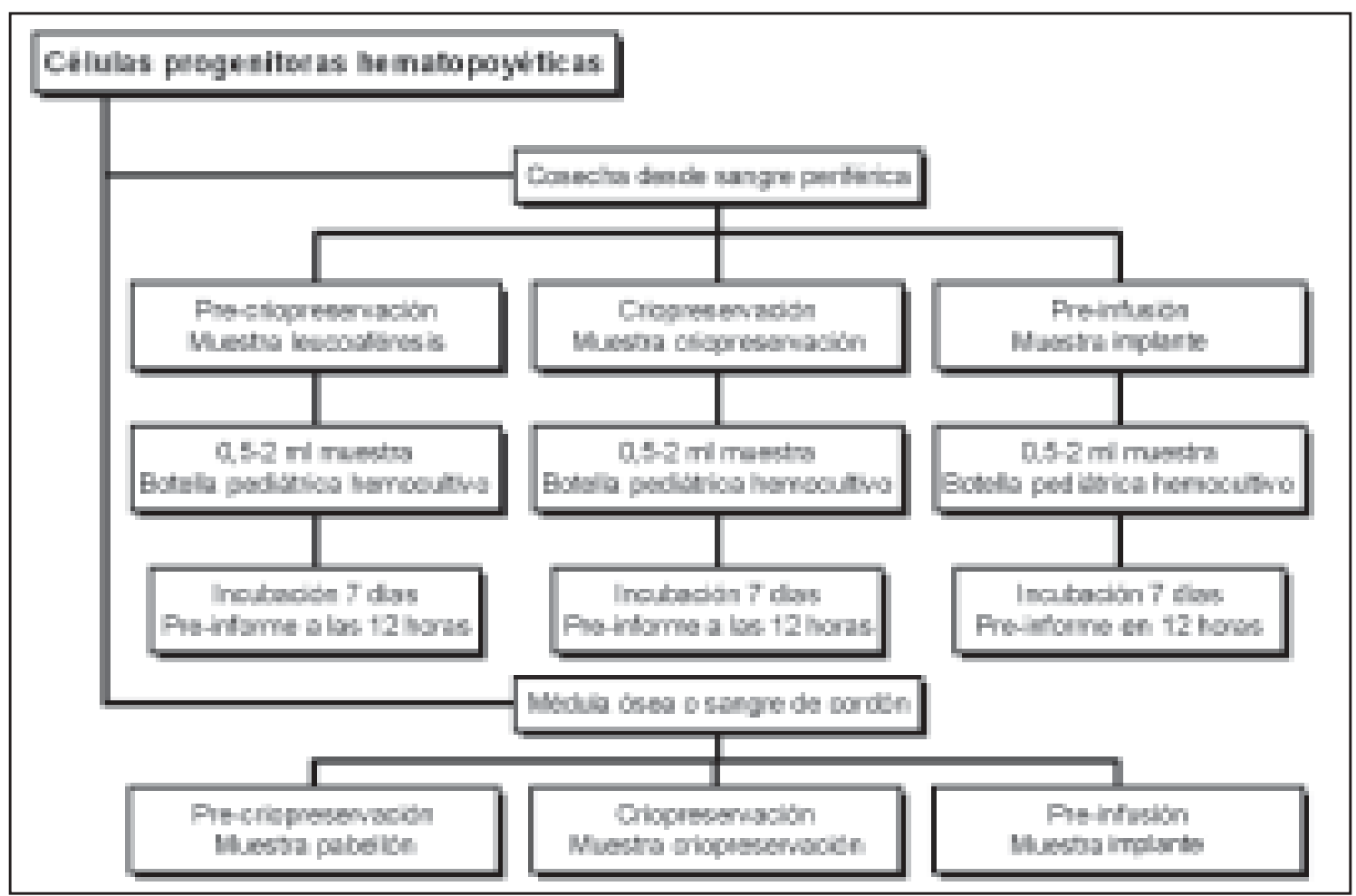

Figura 5. Control microbiológico de las células progenitoras hematopoyéticas.

\section{Post leucoaféresis}

Toma de muestra de la cosecha por leucoaféresis.

Una vez que la bolsa ha llegado al laboratorio de criopreservación, ésta debe ser limpiada externamente con alcohol al $70 \%$ y luego introducida al gabinete de bioseguridad. En estas condiciones, el operador debe usar guantes sólo para su protección y no para proteger el material de la bolsa, dado que éste se manipulará en circuito cerrado y protegido por el flujo laminar vertical del equipo.

- Para obtener una muestra se conecta a la bolsa un acoplador, previa desinfección con povidona yodada. Después de instalado el acoplador, éste se desinfecta y la muestra $(0,5-2 \mathrm{ml})$ se extrae con jeringa $(3 \mathrm{ml})$.

- Desinfecte el tapón de goma de un frasco de hemocultivo pediátrico con alcohol.

- Inocule la muestra en el frasco de hemocultivo.

- Rotule la muestra especificando "muestra leucoaféresis".

- Obtención de muestra de material antes de criopreservar.

Después de obtenida la muestra anterior, el material es procesado en gabinete de bioseguridad, siguiendo la rutina de cada laboratorio.

- Tan pronto como se complete la adición de la solución de criopreservación (medio de cultivo + DMSO \pm plasma isólogo o seroalbúmina humana) a las células y el material sea transferido a las bolsas de criopreservación, con la ayuda de una jeringa ( $3 \mathrm{ml})$, vía llave de 3 pasos del sistema, separe una muestra (1-2 ml).

- Inocule la muestra en un frasco de hemocultivo, según se indica antes.

- Rotule la muestra especificando "muestra criopreservación".

- Las muestras se mantendrán en incubación durante 7 días, con un primer pre-informe a las 12 horas de incubación. En caso que éste indique contaminación, se debe contactar de inmediato con el médico tratante. De confirmarse la contaminación, el personal del Laboratorio de Criopreservación debe descongelar un criotubo control y someterlo a análisis microbiológico, para confirmar o descartar el resultado previo.

Descongelamiento previo a la infusión al paciente: 
- Después de descongelar la bolsa con material criopreservado, introduciéndola en doble bolsa estéril y siguiendo la norma de cada centro de trasplante, la bolsa es limpiada externamente con alcohol al $70 \%$ y enviada envuelta en paño estéril a la sala de trasplante.

- Después que el médico instale en la bolsa, de la bajada de suero se debe obtener una muestra de 1-2 ml y transferirla al frasco de hemocultivo pediátrico, según lo indicado antes.

- Se debe tomar una muestra por cada aféresis realizada al paciente. No es necesario tomar una muestra de cada bolsa en cada aféresis.

- Rotule cada muestra especificando "muestra trasplante", indicando el número de la bolsa y de la aféresis.

Cosecha de células progenitoras de médula ósea o de sangre de cordón umbilical: obtención de muestras para cultivo microbiológico.

Las muestras se deben tomar, siguiendo las indicaciones para "Cosecha de células progenitoras desde sangre periférica", en las siguientes etapas:

- Para la médula ósea: en la bolsa o bolsas enviada (s) desde el pabellón quirúrgico.

Para la sangre de cordón: en la bolsa de recolección enviada desde el pabellón obstétrico

Rotule especificando: "médula ósea pabellón o sangre de cordón pabellón, bolsa".

- Después de completar la adición de la solución de criopreservación (medio de cultivo + DMSO \pm plasma isólogo o seroalbumina humana) a las células y al momento de transferir el material a las bolsas de criopreservación. Rotule "muestra criopreservación".

- Después de descongelar la bolsa con material criopreservado y antes del trasplante. Rotule especificando "muestra trasplante", indicando el número de la bolsa.

\section{Conducta frente a un cultivo positivo}

Los procedimientos de recolección de células progenitoras hematopoyéticas, tanto a partir de médula ósea como de sangre periférica y de cordón umbilical, deben ser realizados bajo condiciones de esterilidad que aseguren obtener un producto no contaminado. El riesgo de contaminación está presente en cualquiera de las etapas de obtención o procesamiento de las células troncales hematopoyéticas (médula ósea o sangre periférica o de cordón umbilical) ${ }^{32,33}$. Por eso, hoy en día es práctica aceptada y obligatoria en todos los laboratorios que manipulan estos productos, la realización de controles microbiológicos adecuados y oportunos para cada etapa del proceso, si bien significa un aumento de los $\operatorname{costos}^{34}$.

En general, un aumento en la incidencia de cultivos positivos ocurre en forma proporcional con el aumento en las etapas de manipulación del producto, tales como eliminación (purging) de exceso de glóbulos rojos o de algún tipo celular tanto normal como tumoral, procedimientos de selección positiva, procedimientos de criopreservación no automatizados, etc.

En estudios realizados con gran número de donantes de células progenitoras, se ha demostrado que la tasa promedio de contaminación de productos después de ser recolectados y antes de la criopreservación es de 1,7\% para médula ósea y de menos de $0,6 \%$ para sangre periférica ${ }^{35}$. En el caso de la médula ósea, el porcentaje de cosechas positivas (que salen de pabellón) es de $2 \%$, y para las células en la etapa de post criopreservación es de $1 \%$ y al momento de descongelar es de $2 \%{ }^{36}$. En el caso de sangre de cordón umbilical, los datos son escasos pues en la mayoría de los casos (bancos públicos), las cosechas contaminadas son procesadas y criopreservadas, pero al momento de confirmación de un cultivo positivo son eliminadas.

Los datos de la literatura demuestran que los microorganismos predominantes que contaminan cosechas de células progenitoras son: bacilos gramnegativos como Pseudomonas sp y grampositivos como Staphylococcus coagulasa negativa, Propionibacterium sp y corineiformes ${ }^{37-39}$.

Hay pocos datos prospectivos en la literatura que evalúen las consecuencias de utilizar cosechas infectadas de células progenitoras hematopoyéticas. En algunos de estos estudios, se han realizado comparaciones en el curso post trasplante de pacientes que recibieran cosechas de médula ósea contaminadas y no contaminadas. Aquellos pacientes infundidos con cosechas contaminadas no mostraron diferencias importantes con pacientes que recibieron médula ósea no contaminada, en cuanto a tiempo de reconstitución hematopoyética, días febriles y/o días con antimicrobianos ${ }^{40,41}$.

Por lo tanto, frente a una cosecha de células progenitoras contaminada, el equipo tratante debe evaluar entre el riesgo de infundir material contaminado pero identificado, con el riesgo de no trasplantar a un paciente que está mielosuprimido, habitualmente producto de altas dosis de quimioterapia.

En aquellos casos en que es imposible obtener una nueva cosecha de células progenitoras, se ha optado por infundir al paciente con las células contaminadas, tomando los resguardos del caso. 


\section{Estudio microbiologico de tejido corneal}

\section{Introducción}

El tejido de córnea utilizado para injerto o queratoplastía penetrante es el botón corneal obtenido de donante cadáver. Este botón se separa del resto de la córnea (anillo y tejido escleral) en el momento de la cirugía del injerto. El anillo exterior de la córnea se utiliza para reparaciones de heridas corneales, injertos lamelares o de parche y epiqueratoplastías (cirugía tectónica no transparente).

Normalmente estos tejidos contienen bacterias de la flora comensal conjuntival y eventualmente otros patógenos, dependiendo de la causa de muerte del dador ${ }^{42,43}$ y del tiempo transcurrido entre la muerte y la enucleación, que no debe ser mayor a 36 horas y en lo posible menor a 6 horas $^{44}$. Por este motivo, en la procuración, pese a realizarse como un acto quirúrgico in vivo, con técnica aséptica e instrumental estéril, el tejido corneal obtenido de la disección del globo ocular se introduce en una solución preservante con antibacterianos y antifúngicos.

Se han utilizado dos métodos de preservación: el cultivo del tejido en medios especiales con antimicrobianos a $34^{\circ} \mathrm{C}$ durante 28 días y la preservación en solución con antimicrobianos a $4^{\circ} \mathrm{C}$ por 2 semanas, siendo este último el procedimiento utilizado en Chile .

Dado que el tejido corneal es un material biológico con flora microbiana comensal no esterilizable y que se somete a un proceso de procuración y preservación susceptible de contaminarse, tiene riesgo de infección que, si bien es bajo, sus consecuencias pueden ser devastadoras.

En distintas comunicaciones ${ }^{45-49}$, la incidencia de endoftalmitis post- implante oscila entre 0,04 y $2 \%{ }^{42}$, pudiendo ser mayor que la asociada a cirugía de catarata $(0,1 \text { a } 0,4 \%)^{42}$. Se considera que al menos en $50 \%$ de estas infecciones, la fuente sería la córnea dadora, aunque no existen estudios de confirmación molecular.

\section{Estudio microbiológico}

Dado los antecedentes encontrados en la literatura, el cultivo rutinario del tejido a injertar es controversial.

Numerosos estudios que realizan cultivos preoperatorios de los anillos corneales y líquidos preservantes han demostrado un grado de contaminación que va de 5 a 30\% ${ }^{50-52}$. La mayoría de los contaminantes son Staphylococcus coagulasa negativa, Streptococcus grupo viridans y hongos. Estos altos niveles de contaminación no tienen impacto clínico siendo la sensibilidad y el valor predictor de ellos cercano a cero, respecto de la aparición de endoftalmitis en estos pacientes $^{43}$. Sin embargo, estos resultados no niegan la asociación de contaminación corneal y endoftalmitis post implante. Cuando se analizó un número importante de endoftalmitis post injerto corneal, se encontró que $56 \%$ de los casos se debían al microorganismo que creció en el anillo ${ }^{51}$. El riesgo de desarrollar endoftalmitis post implante de córneas con cultivo positivo sube de 5,7 a 21 veces para algunos autores. ${ }^{51}$.

Los cultivos de rutina son poco sensibles, tienen bajo valor predictor y los resultados se obtienen después de 72 horas post implante, tiempo crítico para iniciar un tratamiento antimicrobiano adecuado y exitoso, por lo que la utilidad clínica de estos cultivos es muy limitada, excepto en el caso de endoftalmitis por hongos en que está descrito que la fuente es la córnea dadora y se presentan después de las 72 horas de realizado el injerto ${ }^{53}$.

Dado que la contaminación de los tejidos corneales por sí sola no es un marcador de implicancia clínica, que no predice ni descarta una complicación infecciosa post implante, la mayoría de los autores coinciden en que los cultivos rutinarios preoperatorios de los anillos corneales, tejidos esclerales y líquidos preservantes, no son útiles para las decisiones clínicas ni epidemiológicas, ni para asegurar la calidad del procedimiento. Por lo tanto, los bancos de ojos no lo requieren como estándar y son opcionales ${ }^{52}$. El indicador de calidad recomendado para estos bancos es la tasa de endoftalmitis presentadas hasta los 90 días post implante. Se considera que el objeto del banco es proporcionar córneas de alta calidad no necesariamente estériles, pero suficientemente libre de patógenos que puedan provocar infección clínica. Cuando ésta se sospecha se toman cultivos directos de la lesión para adecuar la terapia.

El procedimiento recomendado ${ }^{54}$ en caso de que un banco decida realizar cultivos como parte de sus controles, consiste en (Figura 6):

- Anillo corneal- tejido escleral: después del corte del botón donado siembre directamente en el pabellón quirúrgico en caldo tioglicolato el borde o anillo escleral. Envíe al laboratorio donde se deberá incubar por 5 días. Si no se cuenta con medio de cultivo en el pabellón quirúrgico, envíe el frasco con preservante y tejido al laboratorio para su procesamiento .

- Solución preservante: siembre directamente 2 $\mathrm{ml}$ en caldo tioglicolato. Envíe al laboratorio donde se incubará por 5 días. 


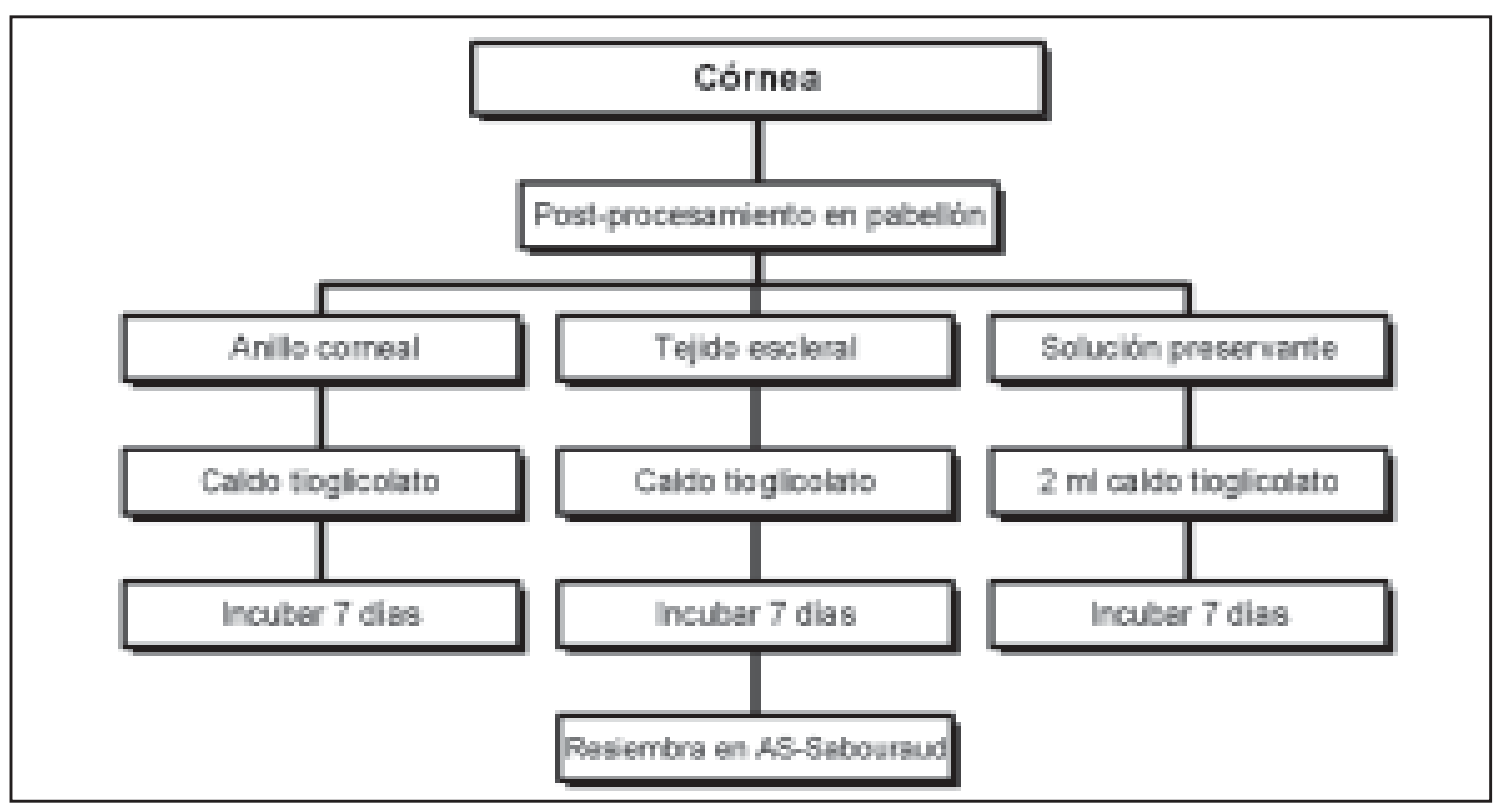

Figura 6. Control microbiológico de córneas para implante. AS: agar sangre.

- Ambas muestras deben ser subcultivadas al quinto día en agar sangre y Sabouraud.

- Cualquier cultivo positivo se identificará de acuerdo a los métodos microbiológicos convencionales, se hará estudio de sensibilidad y se guardará la(s) cepa(s) para estudios epidemiológicos posteriores.

- El laboratorio debe avisar al clínico y al banco de ojos en forma inmediata.

A pesar de que algunos autores han recomendado la siembra directa de estos elementos en agar sangre de cordero, lo que permitiría cuantificar el desarrollo microbiano y a la vez disminuir la contaminación de 18 a $6 \%$, se recomienda mantener la siembra en caldo, dado que facilita la siembra directa en pabellón.

\section{Resumen}

El uso de los implantes de tejido en medicina ha mejorado el pronóstico y/o la calidad de vida de muchas enfermedades, sin embargo, su utilización no está exenta de riesgos para el receptor. Es por esto que la cuidadosa selección del donante vivo o cadáver y el control microbiológico de los tejidos antes de su utilización son procesos muy importantes para asegurar la calidad del procedimiento. La contaminación de los tejidos puede ser intrínseca (por una infección no diagnosticada en el donante) o extrínseca (una vez que el tejido ya ha sido procurado). Estas recomendaciones se refieren al control microbiológico de las contaminaciones extrínsecas, ya sea durante la manipulación, durante la obten- ción de los tejidos o durante el procesamiento para la preservación de ellos. Se analizan los implantes de uso más frecuente en nuestro país (válvulas cardíacas, tejido óseo, piel, células progenitoras hematopoyéticas y córnea) y se describe la metodología según datos existentes en la literatura y de procedimientos adaptados de centros foráneos. Dado que ningún implante es absolutamente estéril es muy importante analizar también las recomendaciones frente a cultivos contaminados. Los autores esperamos que este documento sea de utilidad y que en un futuro próximo, podamos exhibir cifras nacionales multicéntricas con metodologías comparables.

\section{Bibliografía}

1.- Food and Drug Administration. Proposed approach to regulation of cellular and tissue-based products. Rockville, Maryland: US Department of Health and Human Service, Food and Drug Administration, February 1997. http://www.fda.gov/cber/tiss.htm

2.- Bodnar E. Ross D. Valvular Homografts. En Bodnar E. and Frater R. Replacement cardiac valves. Pergamon Press Inc (New York) 1991; 287-306.

3.- O’Brien M, Stafford G, Gardner M A, Pohlner P G, McGiffin D C. A comparison of aortic valve replacement with viable cryopreserved and fresh allograft valves, with a note on chromosomal studies. J Thorac Cardiovasc Surg 1987; 94: 812-23.

4.- Barratt-Boyes B, Roche A, Subramanian R, Pemberton J. Long-term follow-up of patients with the antibioticsterilized aortic homograft valve inserted freehand in the aortic position. Circulation 1987; 75: 768-77.

5.- McNally R, Barwick R, Morse S, Rhodes P. Actuarial analysis of a uniform and reliable preservation method for viable heart valve allografts. Ann Thorac Surg 1989; 48: S83-4. 
6.- Dearani J A, Danielson G K, Puga F J, Schaff H V, Warnes C W, Driscoll D J et al. Late follow-up of 1095 patients undergoing operation for complex congenital heart disease utilizing ventricle to pulmonary artery conduits. Ann Thorac Surg 2003; 75 (2): 399410; discussion 410-1.

7.- O'Brien M F, Harrocks S, Stafford E G, Gardner M A, Pohlner P G, Tesar P J et al. The homograft aortic valve: a 29-year, $99,3 \%$ follow up of 1022 valve replacements. J Heart Valve Dis 2001; 10: 334-45.

8.- Yacoub M. Fourteen-year experience with homovital homografts for aortic valve replacement $\mathrm{J}$ Thorac Cardiovasc Surg 1995; 110: 186-94.

9.- Lund O. Primary aortic valve replacement with allografts over twenty-five years: valve-related and procedure-related determinants of outcome. J Thorac Cardiovasc Surg. 1999 117: 77-91.

10.- Caldarone C, McCrindle B, Van Arsdell G, Freedom R, Williams W. Independent factors associated with longevity of prosthetic pulmonary valves and valved conducts. J Thorac Cardiovasc Surg 2000; 120: 102231 .

11.- Chapman P G, Villar R N. The bacteriology of bone allografts. J Bone Joint Surg (Br) 1992; 74-B: 398-9.

12.- Segur J M, Suso S, García S, Combalía A, Ramón R. Bone allograft contamination in multiorgan and tissue donors. Arch Orthop Trauma Surg 1998; 118: 156-8

13.- Aspenberg P. Bank bone, infections and HIV. Acta Orthop Scand 1998; 69 (6): 557-8.

14.- Lord F, Gebhardt M, Tomford W, Mankin H. Infection in bone allografts: Incidence, nature and treatment. J Bone Joint Surg 1988; 70-A (3): 369-76.

15.- Update: Allograft-associated bacterial infections-United States, 2002. MMWR Morb Mortal Wkly Rep 2002; 51 (10): 207-10.

16.- Bettin D, Harms C, Polster J, Niemeyer T. High incidence of pathogenic microorganisms in bone allografts explanted in the morgue. Acta Orthop Scand 1998; 69 (3): 311-4.

17.- Salmela P M, Hirn M Y, Vuento R E. The real contamination rate of femoral head allografts washed with pulse lavage. Acta Orthop Scand 2002; 73 (3): 317-20.

18.- Veen M R, Bloem R M, Petit P L. Sensitivity and negative predictive value of swab cultures in musculoskeletal allograft procurement. Clin Orthop 1994; 300: 259-63.

19.- Public Health Dispatch: Update: unexplained deaths following knee surgery. Minnesota 2001. MMWR Morb Mortal Wkly Rep December 2001; 50 (48): 1080 .

20.- Farrington M, Matthews I, Foreman J, Caffrey E. Bone graft contamination from a water de-ionizer during processing in a bone bank. J Hosp Infect 1996; (32): 61-4.

21.- Tomford W, Thongphasuk J, Mankin H, Ferraro M J. Frozen musculoskeletal allografts. J Bone Joint Surg 1990; 72-A (8): 1137-43.

22.- Shelton W R, Treacyu S H, Dukes A D, Bomboy A L. Use of allografts in knee reconstruction: I. Basic science aspects and current status. J Amer Acad Orthop Surg 1998; 6 (3): 165-8.

23.- Broz L, Vogtova D, Konigova R. Experience with banked skin in the Prague Burn Center. Acta Chir Plast 1999; 41 (2): 54-8.

24.- Castagnoli C, Alotto D, Cambieri I, Casimiri R, Aluffi M, Stella $\mathrm{M}$ et al. Evaluation of donor skin viability: fresh and cryopreserved skin using tetrazolium salt assay. Burns 2003; 29(8): 759-67.

25.- Hettich R, Ghofrani A, Hafemann B. The immunogenicity of glycerol-preserved donor skin. Burns 1994; 20 Suppl 1: S71-5; Discussion S75-6.

26.- Mericka P, Strakova H, Cermak P, Stepanova V, Hradecky Z, Drahosova M. New safety assurance for biological skin covers. Acta Chir Plast 2002; 44 (1): 23-9.

27.- Bravo D, Rigley TH, Gibran N, Strong DM, NewmanGage H. Effect of storage and preservation methods on viability in transplantable human skin allografts. Burns 2000; 26(4): 367-78.

28.- Mackie D. Postal survey on the use of glycerolpreserved allografts in clinical practice. Burns 2002; 28 Suppl 1: S40-4.

29.- Bourroul S C, Herson M R, Pino E, Matho M B. Sterilization of skin allografts by ionizing radiation. Cell Mol Biol (Noisy-le-grand) 2002; 48 (7): 803-7.

30.- Vuola J, Pipping D. Maintaining a glycerolized skin bank: a practical approach. Burns 2002; 28 Suppl 1: S31-3.

31. - Kearney JN. Quality issues in skin banking: a review. Burns 1998; 24 (4): 299-305. Review.

32.- Rowley S D, Davis J, Dick J, Braine H G, Charache P, Saral R et al. Bacterial contamination of bone marrow grafts intended for autologous and allogeneic bone marrow transplantation. Incidence and clinical significance. Transfusion 1988, 28: 109-12.

33.- Lazarus $\mathrm{H}$ M et al. Contamination during in vitro processing of bone marrow for transplantation: clinical significance. Bone Marrow Transplant 1991; 7: 2416.

34.- Nasser R M, Hajjar I, Sandhaus L M, Hall G S, Avery R K, Bolwell B J et al. Routine cultures of bone marrow and peripheral stem cell harvests: clinical impact, cost analysis and review. Clin Infect Dis 1998; 27: 886-8.

35.- Webb I J, Coral F S, Andersen J W, Elias A D, Finberg R W, Nadler et al. Sources and sequelae of bacterial contamination of hematopoietic stem cell components: implications for the safety of hematotherapy and graft engineering. Transfusion 1996; 36 (9): 782-8.

36.- Prince H M, Page S R, Keating A, Saragosa R F, Vukovic N M, Imrie K R et al. Microbial contamination of harvested bone marrow and peripheral blood. Bone Marrow Transplant 1995; 15: 87-91.

37.- D'Antonio D, Iacone A, Fioritoni G, Dragani A, Betti S, Quaglietta A M et al. Detection of bacterial contamination in bone marrow graft. Haematologica 1991; 76 Suppl 1: 44-5.

38.- Smith D et al. Bacterial contamination of autologous bone marrow during processing. J Hosp Infect 1996; 33: 71-6.

39.- Jestice H K, Farrington M, Hunt C, Matthews I, Scott M A, Marcus R E. Bacterial contamination of peripheral blood progenitor cells for transplatation. Transfus Med 1996; 6: 103-10.

40.- Schwella N, Rick O, Heuft H G, Miksits K, Zimmermann R, Zingsem $\mathrm{J}$ et al. Bacterial contamination of autologous bone marrow: reinfusion of culture-positive grafts does not result in clinical sequelae during the posttransplantation course. Vox Sang 1998; 74: 88-94.

41.- Nifong T P, Ehmann W C, Mierski J A, Domen R E, Rybka W B. Favorable outcome after infusion of coagulase -negative Staphylococci- contaminated peripheral blood hematopoietic cell for autologous transplantation. Arch Pathol Lab Med 2003; 127: e19e21. 
42.- Robert P Y, Camezind P, Drouet M, Ploy M C, Adenis $\mathrm{J}$ P. Internal and external contamination of donor corneas before in situ excision: bacterial risk factor in 93 donors. Graefe Arch Clin Exp Ophthalmol 2002; 240: 265-70.

43.- Pardos D J, Gallagher M A. Microbial contamination of donor eyes. Arch Ophthalmol 1982; 100: 1611-3.

44.- Normativa Nacional de Banco de Ojos. Documento vigente a 2003, de la Corporación de Trasplante de Chile.

45.- Asimakis P, Kirkness C M. Storage of donor corneas, surgery outcome and complications of penetrating keratoplasty. Current Opin Ophthalmol 1996; 7: IV: $35-40$

46.- Ajello L P, Javitt J C, Canner J K. National outcomes of penetrating keratoplasty. Arch Ophthalmol 1993; 11: $509-13$

47.- Cameron J A, Antonios S R, Cotter J B, Habash N R. Endophthalmitis from contaminated donor corneas following penetrating keratoplasty. Arch Ophthalmol 1991; 109: 54-9.

48.- Kattan H M, Flynn H W, Pflugfelder S C et al.
Nosocomial endophthalmitis survey. Current incidence of infection after intraocular surgery. Ophthalmology 1991; 98: 227-38.

49.- Kloess P M, Stulting R D, Waring G, Wilson L A. Bacterial and fungal endophthalmitis after penetrating keratoplasty. Am J Ophthalmol 1993; 115: 309-16.

50.- Wiffen S J, Weston B C, Maguire L J, Bourne W M. The value of rutine donor corneal ring cultures in penetrating keratoplasty. Arch Ophthalmol 1997; 115: 719-24.

51.- Everts R J, Fowler W G, Chang D H, Reller B L. Corneal ring cultures. Cornea 2001; 20 (6): 586-9.

52.- Eye Bank Association of America 2000 Medical Standards. Washington D.C: Eye Bank Association of America, November 2000.

53.- O’ Day M D. Diseases potentially trasmitted through corneal transplantation. Ophthalmology 1989; 96: 1133-8

54.- Wilhelmus K R, Liesegang T J, Osato M S, Jones D B. Laboratory Diagnosis of Ocular Infections. 1994; CUMITECH 13 A. American Society for Microbiology Press.

Correspondencia a:

Patricia García Cañete

E-mail:pgarcía@medpuc.cl 